\title{
Os grandes projetos urbanos como estratégia de crescimento econômico
}

Alberto de Oliveira. Universidade Federal do Rio de Janeiro, Rio de Janeiro, Brasil.

RESUMO | Os grandes projetos urbanos são apresentados como estratégias de desenvolvimento econômico e social. O objetivo desse trabalho é estudar as experiências de São Paulo e do Rio de Janeiro para mostrar os limites, os custos e as potencialidades dessas estratégias. A investigação mostrou que os resultados obtidos não alcançaram os objetivos desejados pelos defensores dos grandes projetos. As populaçóes socialmente vulneráveis atingidas pelos projetos tiveram perdas. Essas experiências serviram para apontar elementos cruciais que devem ser analisados em projetos importantes em curso no Brasil, especialmente a Copa do Mundo e os Jogos Olímpicos.

PALAVRAS-CHAVE | economia urbana, gentrificação, gestão urbana.

ABSTRACT | Large urban projects are presented as a strategy for economic and social development. The aim of this paper is to study the experiences of São Paulo and Rio de Janeiro to understand the limits, costs and potential of large urban projects. The results showed that the goals proposed by defenders of large urban projects were not met. Large projects failed to benefit populations concerned by them. These experiences served to point out crucial elements about the implications of large urban projects. This is very important to Brazil because large projects have been prepared facing the 2014 World Cup and the 2016 Olympic Games.

KEY WORDS | urban economy, gentrification, urban management.

Recibido El 18 de julio de 2011, aprobado el 11 de febrero de 2012

Email: Alberto de Oliveira, alberto.ippur@gmail.com 
Os grandes projetos urbanos são entendidos por seus defensores, como estratégias de crescimento econômico lastreadas nas cidades. Tal conclusão está baseada em dois elementos fundamentais: (1) os elevados recursos envolvidos nos projetos tendem a superar os limites orçamentários da cidade, levando a administração municipal a buscar financiamento em outros níveis de governo e/ou no mercado financeiro e de capitais. (2) as principais justificativas desses investimentos, além do potencial efeito multiplicador, são a atração de investimentos e a geração de renda e emprego.

A realização de grandes projetos urbanos, associados ou não a eventos culturais e esportivos de grande visibilidade internacional, não se constitui novidade na literatura, nem tampouco, na história das grandes cidades europeias e latino-americanas. Nos primórdios da Revolução Industrial, Paris foi palco de importantes projetos urbanísticos que buscaram garantir a modernização da cidade e os meios necessários para a manutenção do processo de acumulação capitalista. A experiência de Barcelona, nos anos 1990, transformou a cidade em modelo de gestão urbana, gerando rebatimentos inconfundíveis em países com diferentes situações socioeconômicas. Na América Latina, a realização de Puerto Madero (Argentina) e as reiteradas tentativas de remodelação da área portuária do Rio de Janeiro são provas concretas do fascínio exercido pelo "modelo Barcelona".

É importante ter em mente que a implantação efetiva de grandes projetos urbanos depende de circunstâncias particulares que são forjadas no entrelaçamento das condiçóes políticas, econômicas e históricas presentes em cada cidade. Retomando o caso de Barcelona, vale lembrar que o aumento da autonomia política e econômica das cidades espanholas (em contrapartida à queda do franquismo) e os vultosos fluxos de investimentos decorrentes do processo de unificação europeia foram fatores decisivos para a implementação daquele projeto urbanístico.

A cidade de Londres, tal como Barcelona, também figura entre os grandes ícones do que ficaria conhecido como "planejamento estratégico". Porém, os ingleses inovaram a experiência ao incorporar novos instrumentos de captação e administração de recursos que aproximavam as relações entre o público e o privado. $\mathrm{Na}$ Inglaterra, replicando o observado nos EUA, foram criadas "agências de desenvolvimento" incumbidas de atribuições urbanísticas de áreas previamente delimitadas. Estas agências foram chamadas de Urban Development Corporations (UDCs). Havia, também, as Housing Associations, empresas de capital misto e voltadas para a construção habitacional e, finalmente, as "Zonas Empresariais", definidas como recortes geográficos do tecido urbano considerados estratégicos, que contavam com incentivos fiscais e financeiros para a atração de empresas.

As UDCs tinham quatro objetivos fundamentais: oferecer terrenos e edifícios para uso efetivo; encorajar o desenvolvimento de atividades comerciais e industriais novas e existentes; atrair o investimento privado; e prover habitações e equipamentos sociais para estimular a ocupação urbana. A estratégia adotada era a de aportar recursos do setor público para incentivar investimentos privados complementares, seja no co-financiamento das obras de infraestrutura ou no desenvolvimento de projetos particulares. Para a gestão da UDC, o governo britânico nomeava um 
comitê, formado por representantes do setor privado e do governo local que, por sua vez, nomeava o diretor geral. As UDCs deveriam prestar contas de seus gastos e realizações mediante relatórios anuais. (Compans, 2004, p. 37)

As UDC's foram bastante criticadas devido à elevada dependência de recursos públicos, o que levantava dúvidas se o modelo realmente criava parcerias efetivas entre o público e o privado ou, simplesmente, transferência de renda. Sabe-se, por exemplo, que as subvenções governamentais corresponderam à metade do valor disponível no orçamento da política urbana, para os anos de 1990 e 1991. As tensões entre o governo local e as UDCs eram ainda maiores nas cidades governadas pelo partido trabalhista, demonstrando o esvaziamento das atribuições do governo local pela política da primeira ministra Thatcher.

$\mathrm{Na}$ renovação da área portuária de Londres (Dockland), dois grupos disputaram o controle do processo: de um lado, as municipalidades trabalhistas defendiam a manutenção do porto e o incentivo à atração de novas indústrias para absorver mão de obra local. De outro, os opositores propunham uma ruptura total com o modelo anterior, priorizando a construção de centros comerciais, de serviços, residências de luxo e a abertura para o capital privado. Em suma, a vitória do modelo baseado nos centros comerciais na batalha pela reformulação da área portuária de Londres, contribuiu para a elevação dos preços da terra e consequente expulsão da população pobre, o que reforçou o contraste e a segregação social.

Os exemplos europeus mostram, com clareza, a complexidade inerente ao modelo de gestão lastreado em grandes intervenções urbanísticas. A identificação dos grandes projetos urbanos como estratégia de crescimento econômico implica, portanto, refletir sobre os motivos que contribuíram para a disseminação dessa lógica no contexto da gestão urbana, seja do ponto de vista teórico, seja no que tange às transformações na economia brasileira a partir da crise dos anos 1980, quando o modelo de crescimento baseado no endividamento externo entrou em colapso. Isso significa afastar modismos em favor da análise serena dos custos e benefícios advindos dos grandes projetos urbanos.

$\mathrm{Na}$ expectativa de contribuir para o debate, este artigo trata das experiências de São Paulo e Rio de Janeiro. Na primeira cidade, estudou-se a Operação Urbana Faria Lima e, na segunda, os Jogos Pan Americanos de 2007. De pronto, vale anotar que os exemplos selecionados, embora referidos a temporalidades, programas e montante de recursos distintos, estão inseridos na mesma lógica econômica. $\mathrm{Ou}$ seja, ambos os projetos são apresentados como estratégias localizadas, capazes de garantir o desenvolvimento econômico.

Por fim, vale a pena lembrar que o Brasil deverá sediar dois eventos de grande repercussão internacional, a Copa do Mundo de 2014 e os Jogos Olímpicos de 2016. Estes projetos, como os investigados nesse texto, vêm sendo justificados como estratégias de desenvolvimento. Portanto, a reflexão sobre as experiências brasileiras recentes pode contribuir para clarear as ideias das ações em curso, não apenas no Brasil, mas, igualmente, em outros países subdesenvolvidos. 
O artigo está organizado em cinco sessões, além dessa introdução. A primeira aborda a lógica econômica dos grandes projetos urbanos. Em seguida, apresentouse o contexto econômico e político brasileiro, particularmente as finanças públicas, de forma a explicitar como o pensamento neoclássico alcançou a gestão urbana. A terceira sessão trata da experiência de São Paulo, seguida pela investigação do Rio de Janeiro. As considerações finais são dedicadas à análise comparativa entre São Paulo e Rio de Janeiro, daí extraindo elementos para o esboço das perspectivas brasileiras no futuro próximo.

\section{Cidades e desenvolvimento econômico}

Os motivos que colocaram as cidades no centro do debate sobre crescimento econômico estão relacionados com as mudanças ocorridas no capitalismo no último quartel do século XX. Em breves traços, a manutenção do pacto baseado nas políticas de bem-estar social exigia a permanente ampliação da produtividade no modelo fordista-keynesiano. Nos anos 1970, quando o crescimento da produtividade começou a declinar, a compressão dos lucros do capital tornou insustentável a manutenção daquele modelo de crescimento econômico. O colapso do keynesianismo abriu caminho para o ressurgimento das políticas de inspiração neoclássica, culminando no conjunto de recomendaçóes consagradas no Consenso de Washington.

Nos países centrais, importantes centros industriais vinham sendo atingidos pelo esvaziamento econômico em razão das novas formas de organização da produção, propiciadas pelo aumento da flexibilidade da localização industrial (Swyngedouw et al.). Num contexto de acirramento da concorrência internacional, a decisão locacional transformou-se em estratégia de redução de custos. Ao lado disso, o avanço tecnológico ampliou as alternativas locacionais, seja pela redução das escalas mínimas de produção, seja integração de informações e processos. Em suma, a indústria se compactou em blocos integrados em busca de sítios que permitissem a captura de externalidades.

A ideia de externalidades está no centro do debate sobre os grandes projetos urbanos. Na teoria econômica, o conceito de externalidade está relacionado aos ganhos obtidos pelas atividades industriais advindos da concentração espacial, pois tal concentração contribuiria para a redução dos custos de instalação de infraestrutura. Nos anos 1980, as experiências dos distritos industriais italianos e a dos polos de tecnologia dos EUA contribuíram para disseminar a ideia de que o desenvolvimento econômico podia ser alcançado, por meio da organização das forças dispersas presentes nas localidades.

O debate sobre o crescimento econômico foi, então, transformado numa guerra de escalas. Alguns autores interpretaram a consolidação dos grandes grupos internacionais como contrapartida ao enfraquecimento dos Estados nacionais que, por sua vez, haviam perdido a capacidade de estabelecer ao setor privado as diretrizes do crescimento econômico, tal como prevaleceu durante a era keynesiana. No lado oposto, o crescimento acentuado de negócios e/ou empresas sediadas em recortes 
geográficos específicos incentivou a ideia de que o comportamento favorável da economia poderia ser obtido por meio do incentivo à inovação e ao empreendedorismo presente na escala local. Novamente, atribuiu-se ao Estado nacional a morosidade e a rigidez que comprometiam o desenvolvimento econômico.

Com o destronamento do Estado como articulador da política econômica, os herdeiros dos economistas neoclássicos buscaram apagar as fronteiras nacionais, elegendo os governos municipais como legítimos representantes na nova ordem econômica mundial. Neste contexto, a cidade metamorfoseada em empresa (Vainer, 2000), deve buscar o seu o lugar no mercado a partir de suas vocações e vantagens comparativas, a fim de atrair investimentos e garantir o desenvolvimento econômico e social. Mais do que qualificar e integrar o território às novas exigências impostas pela globalização, as intervenções urbanas devem proporcionar uma imagem de modernidade ao território (Castells e Borja, 1997).

E mais: o gestor público deve direcionar seus esforços no sentido de integrar as ações pontuais com o planejamento de maior abrangência, a fim de constituir um projeto de Cidade e estabelecer uma "relación vinculante entre el Proyecto Global (más o menos explícito, pero que sea muy asumido por el liderazgo político y cuente con apoyo social) y las actuaciones físicas, debidamente programadas e financiadas" (Castells \& Borja, 1997, p. 221).

No bojo desses princípios, governos locais se lançaram na identificação e divulgação de vocações (que entendiam) capazes de garantir inserção vantajosa na economia internacional. A princípio, todos os municípios são concorrentes no mercado de cidades, a despeito de suas características sociais e econômicas, culminando numa miríade de estratégias de marketing que vão desde a pitoresca auto-titulação (cidade dos morangos, cidade das flores, etc.), passando pela oferta generosa de incentivos fiscais e financeiros, até a disputa pela hospedagem de eventos esportivos de grande visibilidade. O Rio de Janeiro ilustra perfeitamente essa prática, posto que a hospedagem das Olimpíadas de 2016 e a revitalização da área portuária consagram o histórico de tentativas que remontam dos anos 1990.

Assim, a competição de lugares (cidades, estados ou regióes) se incumbiria de prover os incentivos necessários para os investimentos privados. Ao Estado caberia assegurar a estabilidade institucional e fornecer infraestrutura de acordo com as indicações do mercado. Em suma, os teóricos identificados com essa corrente do pensamento econômico entendiam que as rédeas do desenvolvimento deveriam passar do Estado para a iniciativa privada.

Una gran obra infraestructural, como una Ronda perimetral o la reconversión de una zona ferroviaria o fabril, pueden ser también operaciones de redistribución de rentas si garantizan la creación de centralidades accesibles a los sectores populares y mejoran los equipamientos y los servicios de los entornos. (Castells \& Borja, 1997, p. 227)

O pensamento neoclássico, materializado nos grandes projetos urbanos, adequou-se perfeitamente às circunstâncias experimentadas no Brasil. A cartilha neoclássica estabelecia que o Estado deveria se tornar menor e mais eficiente. Para 
tanto, era preciso racionalizar o funcionamento da máquina pública e concentrar os gastos públicos em ações que reforçassem a capacidade de atração de investimentos privados.

Em especial, no Brasil, os ambientes político e econômico encontravam-se sob forte tensão nos anos 1980, gerando impactos não desprezíveis nas cidades. Pela ótica política, o final da ditadura militar abriu caminho para a renegociação do pacto federativo no país, consubstanciado na Constituição de 1988. Do ponto de vista econômico, o modelo de investimento calcado na captação de poupança externa encontrou o seu final derradeiro na crise da dívida externa. O descontrole inflacionário completou o quadro de crônica instabilidade que marcou o período. Para os municípios, criou-se uma situação ambígua: embora a Constituição tenha garantido o acesso a fundos adicionais e ampliado as possibilidades de manejo dos recursos, o longo período de crise comprometeu a capacidade de financiamento do setor público. Ou seja, os municípios ganharam o direito de gastar, mas não havia dinheiro. Assim, o estado de emergência dos níveis de desemprego nos anos 1990, serviu como poderosa ferramenta de legitimação dos grandes projetos urbanos.

Mas como alavancar o investimento diante das restrições de financiamento do setor público? As saídas encontradas para aumentar a capacidade de investimento governamental foram o enxugamento da máquina pública e a criação de mecanismos de racionalização de gastos. O enxugamento limitou-se à privatização da estrutura produtiva estatal que, em muitos casos, mostrou-se controversa. Resultados melhores foram obtidos na racionalização dos gastos a partir da promulgação da Lei de Responsabilidade Fiscal.

É curioso, pois, que a metamorfose da gestão urbana no Brasil tenha ocorrido em meio a amplo processo de ajustamento das contas públicas. Em outras palavras, ainda que a política pública, nos diferentes quadrantes do governo, tenha sido influenciada pelos princípios da teoria neoclássica e pela prática nos países centrais, não restam dúvidas que a crônica instabilidade que caracterizou a economia brasileira nas décadas de 1980/90, restringia a capacidade de investimento do setor público, o que, necessariamente, implicava na definição de prioridades para a destinação dos recursos governamentais.

Os grandes projetos urbanos, transformados em estratégia de desenvolvimento econômico, tornaram-se prioritários em algumas das principais metrópoles brasileiras. Deduz-se, portanto, que os grandes projetos urbanos devem ser entendidos à luz da racionalidade da política macroeconômica e de seus rebatimentos espaciais.

\section{Brasil: abertura política, crise econômica e a adesão ao modelo neoclássico}

No Brasil, a adesão incondicional na gestão baseada na competição de cidades não deve ser creditada exclusivamente à ascensão do pensamento neoclássico. O esgotamento do modelo de crescimento calcado em endividamento externo comprometeu o financiamento dos municípios pelo governo federal, obrigando as cidades a buscar novas alternativas de financiamento. Vale lembrar que a emancipação polí- 
tica dos municípios ocorreu apenas com o término do governo militar, consagrado pela promulgação da Constituição de 1988. Em outros termos, a liberdade política das cidades foi comemorada com os bolsos vazios.

A distensão do ambiente político, nos termos consagrados na Constituição de 1988, permitiu a renegociação da partilha da receita tributária em favor de estados e municípios, ainda que não tenha sido garantida autonomia plena para os últimos, pois dificuldades financeiras permaneceram em razão do aumento das despesas correntes e do estoque de dívidas passadas. Além disso, o governo federal reagiu à perda relativa de receita com a transferência para os municípios de parte das obrigações ligadas às políticas sociais, reforçando a corrosão dos ganhos que os municípios obtiveram com a Constituição (Varsano, 1996).

A interpretação dos efeitos produzidos pela Constituição de 1988 variou de acordo com a posição ideológica adotada pelos analistas. Alguns autores sugerem que a descentralização fiscal teria reduzido a eficácia da gestão pública, pois os gestores municipais tenderiam a ampliar as despesas com a burocracia pública. Varsano (1996) mostrou que, entre 1988 e 1990, os municípios despenderam 30\% da receita adicional, obtida com a reforma constitucional, com o pagamento de salários. De outro lado, o aumento da autonomia orçamentária dos municípios foi interpretado como um benefício para a consolidação da democracia do país. Além disso, não haveria indícios que apontassem para a desqualificação dos prefeitos (comparados aos demais níveis de governo) na gestão do orçamento público. Ainda que tal debate esteja além das fronteiras desse estudo, não restam dúvidas que o padrão de gasto dos recursos públicos se aproximou aos parâmetros preconizados pela ortodoxia econômica, embora distorções ainda possam ser observadas. Dados da Secretaria do Tesouro Nacional mostram que a proporção dos salários no orçamento total dos municípios declinou de 76,1\% para 42,2\%, entre 2000 e 2006.

É importante ter em mente que as mudanças trazidas pela Constituição de 1988 e as medidas de modernização e de transparência da gestão fiscal, incorporadas nos diferentes níveis de governo a partir dos anos 1990, não implicaram em mudanças estruturais na posição relativa entre a união, os estados e os municípios. As informações da Secretaria do Tesouro Nacional mostram que os municípios são dependentes das transferências governamentais, principalmente entre os pequenos aglomerados urbanos. Nos municípios com população entre 10 mil e 50 mil habitantes, as receitas próprias representaram apenas $15,6 \%$ da receita total para o período 1998/2003, enquanto as grandes cidades, com população superior a 1 milhão de habitantes, essa proporção alcançava 51,4\%, no mesmo período.

Em 2000, o governo federal lançou a Lei de Responsabilidade Fiscal (LRF) com o objetivo de racionalizar o gasto público por meio da redução dos gastos com o aparelho burocrático, ampliando o montante de recursos que seriam destinados às atividades prioritárias do Estado. Assim, a LRF estabeleceu limites para os gastos com salários e para o nível de endividamento do Executivo nos três níveis de governo, além de desenvolver instrumentos de controle de receitas e despesas e ampliar a transparência da contabilidade governamental. Entre outras medidas, a 
LRF estabeleceu que os administradores públicos não podem criar novas despesas continuadas sem identificar suas fontes de financiamento ou abrir mão de gastos em outros itens do orçamento. Tal iniciativa buscou mitigar a transferência de obrigações (restos a pagar) entre diferentes gestôes, prática cronicamente presente na política brasileira.

A responsabilidade na gestão fiscal pressupõe a ação planejada e transparente, em que se previnem riscos e corrigem desvios capazes de afetar o equilíbrio das contas públicas, mediante o cumprimento de metas de resultados entre receitas e despesas e a obediência a limites e condições no que tange a renúncia de receita, geração de despesas com pessoal, da seguridade social e outras, dívidas consolidada e mobiliária, operações de crédito, inclusive por antecipação de receita, concessão de garantia e inscrição em Restos a Pagar. (Lei Complementar 101, de 04/05/2000 - Lei de Responsabilidade Fiscal)

A LRF estipulou que o limite máximo de endividamento das prefeituras não pode ultrapassar 1,2 vezes o valor da receita corrente líquida anual. Como a arrecadação está diretamente vinculada ao comportamento do nível de atividade, isso significou, na prática, que a expansão do endividamento estaria ligada diretamente a capacidade de solvência do município. $O$ descumprimento dessa regra implicaria: (a) na proibição de operações de crédito, inclusive de antecipação de receita tributária e (b) no corte de gastos para elevar superávit primário e cobrir o excesso de dívida.

Não restam dúvidas que o aumento da transparência e a penalização (inclusive criminal) do uso irregular de recursos públicos foram avanços incontestáveis trazidos pela Lei de Responsabilidade Fiscal. Há que se considerar, igualmente, que a lei trouxe consigo, como resultado indesejável, o aumento da dependência (política e econômica) dos estados e municípios em relação ao governo federal, posto que o aumento do endividamento somente é possível com a autorização expressa do Ministério da Fazenda. Além disso, cumpre lembrar que a política macroeconômica baseada no controle de preços via juros aumentou consideravelmente as necessidades de financiamento do setor público, em todos os níveis de governo. A armadilha dos juros neutralizou qualquer esforço fiscal de racionamento, posto que, no final das contas, o esforço de contenção de despesas públicas não se transformou em investimento, mas apenas alimentou o serviço da dívida.

Ainda que a Lei de Responsabilidade Fiscal e os grandes projetos urbanos tenham sido concebidos como produto do pensamento neoclássico, não é difícil perceber certa contradição de resultados. De um lado, os grandes projetos dependem de autonomia financeira, estão fundamentados na lógica da descentralização fiscal, política e econômica do Estado e são defendidos pelos supostos benefícios trazidos pela mobilização da "governança" local. No sentido oposto, a Lei de Responsabilidade Fiscal, ao estabelecer limites para o endividamento e rígidas regras de cumprimento do serviço da dívida pública, reduz as margens de manobra dos demais níveis de governo e submete-os ao controle do governo federal. Mais uma vez: sendo a política macroeconômica definida na esfera federal, os esforços de racionalização dos governos subnacionais podem ser neutralizados pelo aumento das taxas de juros. 
Os grandes projetos urbanos tornaram-se atraentes principalmente para as grandes cidades, pois, além de contar com maior base econômica, o capital político de seus administradores ampliava o poder de barganha do município com o governo federal, facilitando o acesso a fontes alternativas de crédito e a captação de fundos através das transferências voluntárias. Para as pequenas cidades, restaram apenas os projetos de traço decorativo. De resto, em ambos os casos, a dependência com os demais níveis de governo é inequívoca. Os projetos selecionados em São Paulo e no Rio de Janeiro buscaram ilustrar a diversidade inerente aos grandes projetos urbanos no Brasil, embora tais iniciativas possam apresentar algumas semelhanças, tais como: os elevados montantes envolvidos, a busca de associação com um ideário de modernidade e a suposta articulação com as diretrizes da economia mundial. A despeito das retóricas, o principal elo que une esses projetos é a promessa de garantir o crescimento econômico, a geração de empregos e a prosperidade dessas cidades, como pode ser observado nas experiências de São Paulo e do Rio de Janeiro.

\section{São Paulo: uma década de intervenções na Faria Lima}

O projeto Faria Lima se refere ao amplo conjunto de ações localizadas no entorno da Avenida Faria Lima, na cidade de São Paulo, visando à reestruturação (ou refuncionalização) da área a fim de incentivar o adensamento de atividades comerciais e de serviços. A principal justificativa para a realização do projeto estava nas supostas vantagens para o crescimento econômico, derivadas da formação de uma nova centralidade de negócios na cidade de São Paulo, ao lado da região central e da Avenida Paulista.

As intervenções na Faria Lima carregaram duas particularidades que as distinguem das demais experiências observadas no Brasil, uma delas ligada aos aspectos políticos do projeto e, a outra, a arquitetura financeira empregada. Do ponto de vista político, é curioso observar que o projeto Faria Lima foi conduzido por duas administraçóes ideológica e historicamente divergentes na cidade de São Paulo. O projeto original foi implementado na gestão do prefeito Paulo Maluf (1993/96), tendo sido aprofundado na gestão da prefeita Marta Suplicy (2001/04).

Do ponto de vista financeiro, o projeto paulistano inaugurou a prática de captação de recursos via mercado financeiro, em resposta às brechas abertas no Estatuto da Cidade, que permitiu a possibilidade de construção acima dos parâmetros estabelecidos na legislação municipal mediante compensação (outorga onerosa). A inovação da capital paulista prende-se a utilização do Certificado de Potencial Adicional de Construção (CEPAC) ${ }^{1}$ como instrumento de financiamento de intervenções urbanas. De acordo com a Prefeitura Municipal de São Paulo (2011a), cerca de R \$ 1,2 trilhão foram obtidos com a negociação de CEPACs, até em março de 2011. Os defensores dos grandes projetos urbanos argumentam em favor do su-

1 Certificados de Potencial Adicional de Construção (CEPAC) são valores imobiliários emitidos pela Prefeitura do Município de São Paulo, por intermédio da EMURB, utilizados como meio de pagamento de contrapartida para a outorga de Direito Urbanístico Adicional, dentro do perímetro de uma Operação Urbana Consorciada. Cada CEPAC equivale a determinado valor de $\mathrm{m}^{2}$ para utilização em área adicional de construção ou em modificação de usos e parâmetros de um terreno ou projeto. 
cesso do projeto Faria Lima, posto que os valores obtidos com os CEPACs teriam superado os gastos realizados naquela região que somavam, no primeiro trimestre de 2011, a quantia de R\$930,3 milhões. Note-se o elevado valor despendido com a administração do projeto ( $\mathrm{R} \$ 74,1$ milhões) que representou quase a metade das despesas com desapropriações (Tabela 1 ).

TABELA 1 | Operação Urbana Faria Lima

\begin{tabular}{l|c}
\hline \multicolumn{1}{c|}{ DESCRIÇÃo DESPESAS } & R\$ X I.000 \\
\hline Obras e Serviços & 678.060 \\
Taxa de Administração & 74.114 \\
Despesas Bancárias, CPMF e Outros & 2.592 \\
Desapropriação & 146.104 \\
Desapropriação - HIS & 7.525 \\
Transporte Coletivo - Metrô & 21.920 \\
\hline Total & $\mathbf{9 3 0 . 3 1 5}$ \\
\hline
\end{tabular}

fonte Prefeitura Municipal de São Paulo (2011)

Os grandes projetos urbanos são criticados, entre outras razões, pela concentração de recursos em pontos específicos da cidade, o que abre a possibilidade de obtenção de ganhos de valorização fundiária para determinados grupos, além de beneficiar uma parcela da população que, usualmente, já conta com situação social privilegiada. De acordo com o prospecto de registro do CEPAC/Faria Lima, "a interligação da Avenida Brigadeiro Faria Lima à Avenida Eng. Luís Carlos Berrini com o prolongamento da Avenida Hélio Pellegrino e o alargamento da Rua Funchal consolidará a região como uma das áreas mais nobres do Município de São Paulo para a implantação de escritórios comerciais (PMSP/Prospecto CEPAC, 2008 p. 148).

Em 2007, quando foi realizado o estudo para o lançamento do $3^{\circ}$ lote de CEPACs, o preço do $\mathrm{m}^{2}$ dos apartamentos novos, situados na área de abrangência do Projeto Faria Lima, variava entre $\mathrm{R} \$ 3.300,00$ e 7.800,00, dependendo do setor de sua localização. Uma pesquisa produzida pelo IBOPE e divulgada na Revista Isto É Exame (2010) mostrou que o preço médio do $\mathrm{m}^{2}$ dos lançamentos imobiliários em bairros periféricos da cidade de São Paulo variou entre R \$2.985,00 (Penha) e R \$ 2.390,00 (Pirituba). Ou seja, a despeito da forte valorização imobiliária experimentada nos últimos anos na cidade de São Paulo, o preço médio dos imóveis novos na periferia não conseguiu alcançar os preços mínimos praticados na região da Faria Lima em 2007. E mais: a valorização dos apartamentos, entre 2004 e 2007, não foi inferior a 9\%, alcançando $29,0 \%$ no setor Pinheiros. O mesmo pode ser observado em relação aos terrenos, cuja valorização registrada atingiu impressionantes 48,0\% no período em foco (Tabela 2).

Os investimentos na Faria Lima, seguindo o roteiro básico de intervenções observadas nas experiências internacionais, privilegiaram os setores ligados ao transporte e circulação. Além dos gastos com desapropriações, parcela relevante dos recursos foi destinada a construção de passagens subterrâneas nas principais artérias 
rodoviárias da região, ao prolongamento e duplicação de avenidas, ao enterramento de cabos elétricos e a construção de áreas de lazer (boulevard). Apenas uma pequena fração dos recursos foi prometida, no projeto original, à construção de habitações populares. No entanto, de acordo com o relatório do projeto, emitido no $1^{\circ}$ trimestre de 2011 (PMSP, 2011b), as ações ligadas à população de baixa renda não haviam sido concluídas, sendo que algumas estariam na fase de estudos.

Não restam dúvidas que os recursos despendidos na Operação Faria Lima (R\$ 930,3 milhões) são significativos quando se considera o diminuto recorte geográfico dos investimentos e a baixa capacidade de apropriação pelas camadas com elevada vulnerabilidade social. Tomando os relatórios trimestrais de acompanhamento das CEPACs entre o $1^{\circ}$ trimestre de 2005 e o $4^{\circ}$ trimestre de 2010, é possível constatar que os gastos médios anuais na Faria Lima alcançaram a soma de R \$62,1 milhões. No mesmo período, o investimento médio da prefeitura paulistana somou $\mathrm{R} \$ 1,4$ trilhões. Isso significa que, em média, os gastos com a Faria Lima corresponderam a cerca de $4,4 \%$ do investimento total. Em suma, não se pode admitir que o poder público coloque parcela relevante dos seus "ovos" numa única cesta, tendo em vista o déficit social presente na periferia da cidade.

Por fim, resta apenas ponderar que os valores envolvidos na Faria Lima perdem relevo quando comparados com a totalidade das despesas da prefeitura, pois os gastos com a Faria Lima representaram apenas $0,5 \%$ do total das despesas realizadas entre 2004 e 2008, enquanto a participação das despesas com Urbanismo (11,6\%), Saúde $(21,3 \%)$ e Educação $(17,7 \%)$ alcançaram níveis mais elevados, no mesmo período.

TABELA 2 | Intervalo e evolução do preço médio por $\mathrm{m}^{2} \mathrm{da}$ área de abrangência do projeto Faria Lima.

\begin{tabular}{|c|c|c|c|c|}
\hline \multirow[b]{2}{*}{ SETOR } & \multicolumn{2}{|c|}{ TERRENOS } & \multicolumn{2}{|c|}{ APARTAMENTO PADRÃO } \\
\hline & $\begin{array}{l}\text { Valor em m }{ }^{2} \\
\text { (em R } \$ \text { de 2007) }\end{array}$ & $\begin{array}{l}\text { Variação \% } \\
(2004 / 07)\end{array}$ & $\begin{array}{l}\text { Valor em m }{ }^{2} \\
(\text { em R } \$ \text { de 2007) }\end{array}$ & $\begin{array}{l}\text { Variação \% } \\
(2004 / 07)\end{array}$ \\
\hline Pinheiros & $2.100,00$ a $4.900,00$ & 48 & $3.300,00$ a $3.600,00$ & 29 \\
\hline Faria Lima & $2.900,00$ a $6.600,00$ & 17 & $6.800,00$ a $7.800,00$ & 9,6 \\
\hline Helio Pellegrino & $2.500,00$ a $6.800,00$ & 36,7 & $4.000,00$ a $4.700,00$ & 9,5 \\
\hline Olimpíadas & $2.500,00$ a $4.500,00$ & 15,9 & $3.500,00$ a $3.700,00$ & 9,7 \\
\hline
\end{tabular}

fonte Prefeitura Municipal de São Paulo (2008)

NOTA A ÁREA DE ABRANGÊNCIA Do PROJETO FARIA LIMA FOI RE

\section{Rio de Janeiro: a cidade esportista}

O desempenho da economia do Estado do Rio de Janeiro, no último quartel do século XX e nos anos posteriores, refletiu os resultados produzidos pelo Plano Real no âmbito das mudanças na divisão regional do trabalho no Brasil. Ainda que a economia fluminense tenha sofrido os efeitos deletérios produzidos pela política macroeconômica de inspiração neoclássica, notadamente o aumento do desempre- 
go e do déficit público, o Rio de Janeiro a exemplo do ocorrido nos demais quadrantes do espaço nacional, também colheu resultados favoráveis no novo cenário econômico. A histórica trajetória de decadência do estado foi interrompida a partir dos anos 90, tendo o crescimento alcançado, em alguns anos, porcentagens mais elevadas que a média nacional (Natal \& Oliveira, 2005).

A nova orientação macroeconômica trouxe consigo importantes mudanças para a economia fluminense, com destaque para a captação de investimentos (públicos e privados) por meio da revitalização da infraestrutura e da criação de novas plantas produtivas. No entanto, a grande virada da economia estadual foi puxada pela quebra do monopólio do petróleo, em 1997. O potencial de exploração da Bacia de Campos transformou o Rio de Janeiro no destino natural dos vultosos investimentos ligados a Indústria do Petróleo, gerando efeitos positivos sobre os diferentes ramos industriais, o nível de arrecadação e as instituições produtoras de conhecimento.

As mudanças no quadro macroeconômico não significaram, é claro, a solução definitiva para os problemas da economia fluminense. Além disso, não se pode perder de vista o caráter provisório inerente à exploração mineral como sustentáculo do crescimento econômico e da previsível disparidade entre a expansão da riqueza disponível e a redução das desigualdades sociais. É impossível negar, entretanto, que os recursos trazidos pelo petróleo tiveram impacto relevante sobre a economia estadual. A cidade do Rio de Janeiro, em especial após o ajustamento causado pela mudança da capital federal, remodelou o seu papel na economia estadual reafirmando sua função de provedora de serviços modernos, enquanto o entorno metropolitano reforçou suas heranças através da consolidação da Indústria Metal-mecânica e da Petroquímica. Cumpre saber, portanto, o que isso significou para a cidade do Rio de Janeiro.

A cidade do Rio de Janeiro vem perdendo população para a região metropolitana e para o interior do estado. Entre 1996 e 2008, a participação da capital na população estadual declinou de $41,4 \%$ para $39,0 \%$, respectivamente. Tal movimento não representa novidade, tampouco reflete comportamento diferenciado em relação às demais metrópoles brasileiras. No entanto, o que chama a atenção é o fato de que as atividades econômicas com maior potencial de crescimento estão localizadas fora da cidade do Rio de Janeiro, ainda que a capital fluminense não tenha perdido sua posição de centralidade na economia estadual.

O processo de readequação da posição da cidade do Rio de Janeiro na divisão do trabalho gerou reflexos não desprezíveis na dinâmica do mercado de trabalho. O desempenho favorável da economia brasileira, sobretudo a partir de 2003, contribuiu para a melhoria do mercado de trabalho, não apenas no Rio de Janeiro, mas nas principais metrópoles brasileiras. De acordo com a Pesquisa Mensal de Emprego (PME/IBGE), em 2008, a taxa média de desemprego da Região Metropolitana do Rio de Janeiro $(6,8 \%)$ esteve entre as menores do país, perdendo, apenas, para Belo Horizonte e Porto Alegre (6,5\% e 5,9\%, respectivamente). Na área metropolitana paulista, a taxa de desemprego alcançou 8,4\%, no mesmo ano. Tal resultado representou a consolidação da tendência de declínio registrada na década de 2000 em todas as regiões abrangidas pela pesquisa do IBGE. 
Ora, se as mudanças na política macroeconômica, a despeito dos seus custos sociais, contribuíram decisivamente para a atração de investimentos, se os níveis de desemprego apresentaram trajetória declinante e se os processos de ajustamento da metrópole fluminense seguem o padrão observado em outras regiões metropolitanas brasileiras, quais são as justificativas para eleger a realização de grandes eventos esportivos como estratégia de crescimento econômico? Tais investimentos são capazes de alterar tendências econômicas mais amplas? Quanto isso custou para os cofres da cidade?

A realização dos Jogos Pan-americanos do Rio de Janeiro, em 2007, foi saudada como estratégia de desenvolvimento para cidade e embalada na promessa de geração de empregos, na realização de investimentos em infraestrutura e na divulgação da imagem do Rio de Janeiro no âmbito internacional. De acordo com o Tribunal de Contas da União (TCU, 2008), foram consumidos R \$ 3,5 bilhões na realização dos jogos pan-americanos, quantia que pode alcançar patamares ainda maiores, posto que os valores despendidos pelo governo do Estado do Rio de Janeiro e pelos parceiros privados não foram contabilizados no referido relatório. A Prefeitura Municipal do Rio de Janeiro arcou com 33,7\% dos gastos ( $\mathrm{R} \$ 1,2$ bilhão), enquanto o governo federal comprometeria pouco menos da metade ( $\mathrm{R}$ \$ 1,6 bilhão) dos gastos do evento, sendo o restante assumido, principalmente, pelo governo estadual.

O levantamento dos gastos com os jogos, que foi possível somente após a conclusão do evento, desfez o mito da participação do capital privado, pois os R 153 milhões investidos pelas empresas privadas corresponderam a apenas $4,3 \%$ do gasto total. Em contrapartida, a União despendeu $\mathrm{R} \$ 1,6$ bilhão nos jogos e, adicionalmente, mobilizou empresas estatais de grande porte para garantir recursos com propaganda e patrocínio. A Caixa Econômica Federal, a Petrobrás e os Correios, juntos, gastaram $\mathrm{R} \$ 16,3$ milhões em patrocínio, valor que superou o obtido junto ao setor privado ( $\mathrm{R} \$ 8,1$ milhões) (TCU, 2008).

Dentre os gastos realizados nos jogos, parcela expressiva foi destinada à segurança, demonstrando o receio dos organizadores que a violência cotidiana do Rio de Janeiro pudesse comprometer a imagem da cidade e o marketing relacionado ao evento. Note-se que os investimentos com segurança realizados pelo governo federal ( $\mathrm{R} \$ 562,1$ milhões) superaram os destinados à infraestrutura esportiva permanente ( $\mathrm{R} \$ 451,7$ milhões).

O governo federal despendeu $\mathrm{R} \$ 362,9$ milhóes em serviços de suporte aos jogos. Foram gastos $\mathrm{R}$ \$ 60,9 milhões com os serviços de áudio e vídeo, $\mathrm{R}$ \$ 46,8 milhões com telecomunicações e R \$31,9 milhões com hotelaria, entre outros itens. Somente as cerimônias de abertura e de encerramento dos jogos consumiram $\mathrm{R} \$ 47,9$ milhões. Além disso, as atividades administrativas consumiram outros $\mathrm{R} \$ 188,9$ milhões.

É curioso que a operacionalização dos jogos tenha consumido cerca de $1 / 3$ dos gastos com infraestrutura esportiva, posto que a somatória dos gastos com suporte aos jogos com as despesas administrativas totalizaram $\mathrm{R} \$ 551$ milhôes de reais, enquanto os investimentos em infraestrutura (prefeitura + governo federal) alcançaram $\mathrm{R} \$ 1,7$ bilhão. 
É intrigante observar que uma das principais razões que justificariam a realização dos Jogos Pan-americanos, o legado de infraestrutura para a cidade, não tenha ocupado posição relevante na lista de gastos do governo federal. Os gastos com infraestrutura de consumo coletivo somaram apenas $\mathrm{R} \$ 54,2$ milhões, representando apenas 3,4\% do investimento da União. E mais: praticamente a totalidade desse investimento foi realizado às margens da Vila do Pan, condomínio de classe média alta que foi construído com financiamento subsidiado pela Caixa Econômica Federal. O TCU foi enfático:

Talvez a infraestrutura urbana tenha sido a área que menos benefícios obteve a partir da realização dos Jogos Pan-americanos. Nenhuma obra de relevância foi planejada ou realizada na cidade do Rio de Janeiro em decorrência do evento. Ao contrário, algumas iniciativas de intervenções viárias, imaginadas a partir da candidatura da cidade à sede dos Jogos Olímpicos de 2012, e que acabaram sendo carreadas nos planos para os Jogos Pan-americanos, foram arquivadas sem que ao menos fossem iniciadas. Mesmo em face da quase total ausência de intervenções no setor, não houve maiores prejuízos à realização dos Jogos. (TCU, 2008, p. 117).

Ainda que os legados do Pan-americano possam ser questionados, é indiscutível que recursos públicos significativos foram empenhados nessa estratégia. Entre 2003 e 2007, os gastos da prefeitura do Rio de Janeiro alcançaram R \$ 47,1 bilhões, sendo que os jogos pan-americanos consumiram 2,8\% deste total. A magnitude das despesas dos jogos no orçamento municipal é visível quando se observa que o valor empenhado no evento, somente pela prefeitura (R $\$ 1,2$ bilhão), correspondeu a cerca de $1 / 6$ das despesas realizadas com saúde ( $\mathrm{R} \$ 8,6$ bilhões) ou educação ( $\mathrm{R} \$ 8,5$ bilhões), funções de governo com grande peso no orçamento e elevada amplitude social.

A realização dos jogos, no entanto, não alterou a lógica de racionamento das despesas públicas imposta pela Lei de Responsabilidade Fiscal, ou seja, a prefeitura do Rio de Janeiro fez a sua "lição de casa". Entre 2003 e 2007, o município acumulou superávit de $\mathrm{R} \$ 1,1$ bilhão, além de destinar outros $\mathrm{R} \$ 4,1$ bilhões para o pagamento de juros e amortização de dívidas. Em outras palavras, pouco mais de $10 \%$ das despesas totais do município foi utilizado de acordo com os princípios da "boa governança” presentes nos manuais da economia neoclássica. Esse montante seria suficiente para elevar em mais de $50 \%$ os gastos com saúde, cujo desempenho é historicamente abaixo do desejável. Ora, se o governo da cidade do Rio de Janeiro sacrificou funções que afetam largamente o bem-estar da população em nome do equilíbrio fiscal e da redução do endividamento, por que gastar $\mathrm{R} \$ 1,3$ bilhão com um megaevento esportivo? Refrescando a memória: os gastos com os jogos pan-americanos equivaleram a $117,8 \%$ do superávit fiscal do período e $31,4 \%$ das despesas com juros e amortizações.

Resumindo, o governo da cidade do Rio de Janeiro mobilizou R \$ 1,2 bilhão para a realização de evento esportivo com resultados questionáveis, pois: (1) o megaevento não atendeu as promessas originais (a disseminação do esporte como atividade social e o aproveitamento das arenas para eventos esportivos internacionais); (2) as arenas esportivas foram transferidas para a iniciativa privada em razão dos altos custos de manutenção não suportados pelo governo; (3) os investimentos 
em serviços e infraestrutura coletiva para a população local, notadamente a de baixa renda, foram desprezíveis; (4) os investimentos do setor privado foram marginais; (5) os gastos nos jogos consumiram parcelas expressivas do orçamento municipal, sem mencionar os investimentos realizados pelo governo federal e (6) os impactos sobre o mercado de trabalho foram indetectáveis (Oliveira, 2010).

\section{Consideraçôes finais: o que o futuro reserva?}

Este trabalho buscou investigar os limites e potencialidades dos grandes projetos urbanos como instrumento para alcançar o crescimento econômico, asseveram seus defensores, bem como seus efetivos impactos sobre as contas públicas e os serviços coletivos prestados pelo setor governamental. Em primeiro lugar e contrariando o discurso oficial, as experiências observadas em São Paulo e no Rio de Janeiro tornam claro que as iniciativas em pauta não se sustentariam sem o decisivo aporte financeiro do setor público. No caso carioca, em especial, a realização dos jogos Pan-americanos contou com expressivo montante de recursos federais. Cai por terra, desde logo, a ideia dos grandes projetos urbanos como catalisadores do investimento privado.

Ainda que se considere a existência de efeitos sobre o mercado de trabalho, sobretudo na Construção Civil, é inegável que uma parcela dos postos de trabalho criados tem perfil temporário, extinguindo-se ao cabo das obras. O importante a reter é que os projetos em pauta, em ambas as cidades, não implicaram em alterações estruturais na economia daquelas cidades. Em São Paulo, Oliveira (2005) demonstrou que, entre 1996 e 2000, a criação de 16.316 empregos no eixo Berrini/Águas Espraiadas (que integra o projeto Faria Lima) foi contrabalançada pela eliminação de 8.317 postos de trabalho na região central de São Paulo, sugerindo, apenas, o rearranjo geográfico de parte do Setor Terciário. Já no Rio de Janeiro, a concentração de gastos na construção de arenas esportivas e aparatos de segurança, bem como o diminuto período de realização dos jogos não apontam, tampouco, para mudanças de caráter permanente na cidade.

No entanto, se não existem provas concretas de que os grandes projetos urbanos contribuíram efetivamente para alavancar o crescimento econômico das cidades estudadas, o mesmo não se pode dizer a respeito dos impactos sobre as contas públicas. Embora esses projetos tenham sido concebidos a partir de matrizes teóricas e ideológicas semelhantes, devido ao tamanho relativo das cidades envolvidas, seus efeitos sobre as contas públicas foram diferenciados. A Tabela 3 mostra que São Paulo levou 10 anos para consumir $\mathrm{R} \$ 930$ milhões, enquanto o Rio de Janeiro despendeu R \$ 1,2 bilhão em apenas 4 anos. O peso do projeto Faria Lima nas despesas municipais foi menor que os encargos criados pelos jogos Pan-americanos $(0,5 \%$ e 2,8\%, respectivamente). Tal discrepância foi potencializada pelas diferenças de tamanho entre São Paulo e Rio de Janeiro, pois, enquanto os cariocas pagaram, em média, R\$199,00 para sediar o Pan, os paulistanos arcaram com R\$ 85,46 para construir a Faria Lima. Em suma, os sacrifícios infligidos pelos grandes projetos aos moradores do Rio de Janeiro foram maiores que os de São Paulo. 
TABELA 3 | Grandes projetos urbanos em São Paulo e no Rio de Janeiro

\begin{tabular}{|c|c|c|}
\hline PROJETO & $\begin{array}{l}\text { OPERAÇÃo FARIA LIMA } \\
\text { SÃO PAULO }\end{array}$ & $\begin{array}{l}\text { JOGOS PAN-AMERICANOS } \\
\text { RIO DE JANEIRO }\end{array}$ \\
\hline Gastos realizados & R\$ 930 milhões ${ }^{(1)}$ & R\$ 1,2 bilhão ${ }^{(2)}$ \\
\hline Período de realização dos gastos & 10 anos & 4 anos \\
\hline $\begin{array}{l}\text { Participação das despesas do } \\
\text { projeto em relação ao total de } \\
\text { gastos da prefeitura }\end{array}$ & $0,5 \%$ & $2,8 \%$ \\
\hline $\begin{array}{l}\text { Gasto médio do projeto por } \\
\text { habitante }^{(3)}\end{array}$ & $\mathrm{R} \$ 85,46$ & $\mathrm{R} \$ 199,00$ \\
\hline
\end{tabular}

FONTE ELABORAÇÃO DO AUTOR.

Notas (1) SAldo aCUMUlado até 2011. (2) Gastos SOMENTE da PREFeitura. (3) Base de CÁlCulo: CONTAGEM POPUlaCIONAL IBGE/2007 (SÃo PAUlo $=10.886 .518$ HABITANTES E RIO DE JANEIRO = 6.093.472 HABITANTES).

A aceitação da candidatura do Rio de Janeiro para sediar as Olimpíadas de 2016 e parte das competições da Copa do Mundo de 2014 abriu novos e importantes flancos para a manutenção da estratégia de crescimento por meio da realização de grandes projetos urbanos, nesse caso, eventos esportivos com ampla visibilidade internacional. De pronto, destaque-se a mudança de patamar dos recursos envolvidos. Somente para as Olimpíadas, o orçamento inicial prevê gastos da ordem de $\mathrm{R} \$ 30$ bilhões.

Infelizmente, o padrão que vem sendo observado nos gastos das Olimpíadas não difere, substancialmente, com o registrado nos Jogos Pan Americanos, pois serviços coletivos de amplo alcance social não receberão aportes relevantes de recursos públicos ou privados. Dentre os recursos destinados ao transporte público, item importante da pauta de investimentos das Olimpíadas, parcela expressiva será aplicada em modalidades e roteiros que não atendem plenamente a população socialmente vulnerável do Rio de Janeiro. No sentido oposto, a distribuição geográfica dos investimentos e as recentes mudanças na legislação urbanística apontam, claramente, a priorização de sítios dotados de vazios urbanos e espaços subutilizados com elevado potencial de valorização, tais como o entorno da Barra da Tijuca e a região portuária.

Tais elementos são apenas alguns exemplos de uma lista praticamente infindável de questóes que justificam o debate sereno sobre a alocação setorial e geográfica dos recursos públicos no Rio de Janeiro. Afastando-se o ufanismo que cerca os preparativos das Olimpíadas de 2016 em favor da análise ponderada de custos e benefícios, pode-se evitar que a política de desenvolvimento social e econômico se torne refém dos megaeventos ou de quaisquer das modalidades dos grandes projetos urbanos. OEURE 
De Oliveira | Os grandes projetos urbanos como estratégia de crescimento... | @EURE

\section{Referências bibliográficas}

Castells, M., \& Borja, J. E. (1997). Planes estratégicos y proyectos metropolitanos. Cadernos IPPUR, $11(1$ e 2$), 17-35$.

Compans, R. 2004. Intervenções de recuperação de zonas urbanas centrais: experiências nacionais e internacionais. In Emurb (Empresa Municipal de Urbanização), Cebrap (Centro Brasileiro de Análise e Planejamento) e CEM (Centro de Estudos da Metrópole) (Orgs.), Caminhos para o centro. Estratégias de desenvolvimento para a região central de São Paulo (pp. 23-60). São Paulo: Emurb.

Natal, J. L. \& Oliveira, A. (2005). Crescimento econômico interiorano e condições de vida. In J.L. Natal (Org.), O Estado do Rio de Janeiro Pós-1995: dinâmica econômica, rede urbana e questão social (pp 2-40). Rio de Janeiro: Pubblicati Editora.

Oliveira, A. (2005). Planejamento urbano e geração de empregos: a cidade de São Paulo (Brasil) nos anos 90. EURE, 31(92), 47-64. Disponível em: http://www.scielo.cl/scielo. php?pid=S0250-71612005009200003\&script $=$ sci_arttext

Oliveira, A. (2010). Mega-events, urban management and macroeconomic policy: The 2007 Pan American Games in Rio de Janeiro. Journal of Urban Planning and Development, 137(2), 184-192. doi: 10.1061/(ASCE)UP.1943-5444.0000054

Prefeitura Municipal de São Paulo (PMSP). (2008). Prospecto de Registro da Operação Urbana Consorciada Faria Lima. Versão atualizada em julho de 2008. Disponível em http://www.bmfbovespa.com.br/pt-br/mercados/download/FariaLima030209B.pdf

Prefeitura Municipal de São Paulo (PMSP). (2011a). Operação Urbana Consorciada Faria Lima. Resumo da operação financeira até 31/03/2011. Disponível em http://www.prefeitura.sp.gov. br/cidade/secretarias/upload/desenvolvimento_urbano/sp_urbanismo/arquivos/oufl/ ouc_faria_lima_31_mar_11_resumo_financeiro.pdf

Prefeitura Municipal de São Paulo (PMSP). (2011b) Operação Urbana Consorciada Faria Lima. Relatório trimestral (instrução CVMn. 401/2003) relativo a Operação Urbana Consorciada Faria Lima (CEPAC). Versão relativa ao $1^{\circ}$. trimestre de 2011. Disponível em http://www.bmfbovespa.com.br/pt-br/mercados/download/FariaLima-Relatorio-1Trimestre-2011.pdf

Revista Isto é Exame. (2010). Pesquisa de imóveis do Ibope 2010. Disponível em http://exame.abril. com.br/seu-dinheiro/imoveis/infograficos/pesquisa-de-imoveis-do-ibope-2010/

Secretaria do Tesouro Nacional/Governo Federal. (2011). Estatísticas para Estados, Municípios e União. http://www.tesouro.fazenda.gov.br/estados_municipios/index.asp

Tribunal de Contas da União (TCU) (2008). Acórdão 2101/2008. Disponível em http://contas.tcu. gov.br/portaltextual/MostraDocumento q $\mathrm{q}=1 \& \mathrm{doc}=5 \& \mathrm{dpp}=20 \& \mathrm{p}=0$.

Vainer, C. (2000). Pátria, empresa e mercadoria: notas sobre a estratégia discursiva do planejamento estratégico urbano. In O. Arantes et al. (Orgs.), A cidade do pensamento único: desmanchando consensos. (pp. 64-92). São Paulo: Vozes. 